\title{
PERCEPÇÃO DOS IMPACTOS SOCIOAMBIENTAIS DA IMPLANTAÇÃO DE PARQUES EÓLICOS NA COMUNIDADE DE PONTA DO MEL, AREIA BRANCA/RN
}

Fabiana Ferreira ${ }^{1}$ Ramiro Camacho² Rodrigo Guimarães ${ }^{3}$

Resumo: Devido as características físicas favoráveis - alta incidência de ventos fortes e constantes, o estado do Rio Grande do Norte (RN), investe na implantação de parques de energia eólica, principalmente nos municípios situados na zona costeira, ocasionando diversos os impactos socioambientais. O presente artigo tem o objetivo de identificar esses impactos, através da percepção ambiental dos moradores da comunidade de Ponta do Mel/RN, mediante aplicação de um questionário semiestruturado. Foram observados que $85,71 \%$ apoiariam a instalação de novos parques eólicos. Com esse resultado foi possível observar que os critérios locacionais utilizados para implantação dos parques foram favoráveis ao local.

Palavras-chave: Energia Renovável. Comunidades Tradicionais. Percepção Ambiental. Impactos Socioambientais. Semiárido.

\section{PERCEPTION OF THE SOCIO-ENVIRONMENTAL IMPACTS OF THE IMPLEMENTATION OF WIND FARMS IN THE COMMUNITY OF PONTA DO MEL, AREIA BRANCA/RN}

Abstract: Due to favorable physical characteristics - high incidence of strong and constant winds, the state of Rio Grande do Norte (RN) invests in the implantation of wind energy parks, mainly in the municipalities located in the coastal zone, causing several social and environmental impacts. This paper aims to identify these impacts through the environmental perception of the residents of the community of Ponta do $\mathrm{Mel} / \mathrm{RN}$, through the application of a semi - structured questionnaire. It was observed that $85.71 \%$ would support the installation of new wind farms. With this result it was possible to observe that the locational criteria used to implement the parks were favorable to the site.

Keywords: Renewable Energy. Traditional Communities. Environmental Perception. Socioenvironmental Impacts. Semi-arid.

\section{PERCEPCIÓN DE LOS IMPACTOS SOCIOAMBIENTALES DE LA IMPLANTACIÓN DE PARQUES EÓLICOS EN LA COMUNIDAD DE PONTA DO MEL, AREIA BRANCA/RN}

Resumen: Debido a las características físicas favorables - alta incidencia de vientos fuertes y constantes, el estado de Rio Grande do Norte (RN), invierte en la implantación de parques de energía eólica, principalmente en los municipios

\footnotetext{
${ }^{1}$ Universidade do Estado do Rio Grande do Norte - UERN, Gestão Ambiental, Mossoró, Brasil, fabianaksm@yahoo.com.br, https://orcid.org/0000-0002-6441-8663

2 Universidade do Estado do Rio Grande do Norte - UERN, Ciências Biológicas, Mossoró, Brasil, ramirogustavovc@gmail.com, https://orcid.org/0000-0002-1259-0373

${ }_{3}^{3}$ Universidade do Estado do Rio Grande do Norte - UERN, Gestão Ambiental, Mossoró, Brasil, rodrigocarvalho@uern.br, https://orcid.org/0000-0001-6701-9994
} 
situados en la zona costera, ocasionando diversos impactos socioambientales. El presente artículo tiene el objetivo de identificar esos impactos, a través de la percepción ambiental de los habitantes de la comunidad de Ponta do Mel/RN, mediante la aplicación de un cuestionario semiestructurado. Se observó que $85,71 \%$ apoyaría la instalación de nuevos parques eólicos. Con ese resultado fue posible observar que los criterios locacionales utilizados para implantación de los parques fueron favorables al local.

Palabras clave: Energía Renovable. Comunidades Tradicionales. Percepción Ambiental. Impactos Socioambientales. Región Semiárida.

\section{Introdução}

Vários acontecimentos ou fenômenos ambientais, dentre eles a intensificação da industrialização e o consequente aumento da capacidade de intervenção do homem na natureza, marcaram a crescente preocupação com as causas ambientais e um dos mais importantes documentos para examinar as relações entre o meio ambiente e o desenvolvimento foi Relatório de Brundtland, da Comissão Mundial para o Meio Ambiente (CNMAD, 1991), denominado de "Nosso Futuro Comum", este sendo referência e base importante para os debates que aconteceram na Conferência das Nações Unidas sobre o Meio Ambiente no Rio de Janeiro em 1992.

Dentro desse contexto da crise ambiental, o tema da produção de energia tem tido um papel fundamental, em especial a partir da Rio 92 e da Convenção-Quadro das Nações Unidas sobre Mudanças Climáticas, o que vem gerando propostas, políticas e programas de reconfiguração da matriz energética em vários países. Ao considerar as formas de como a sociedade apropria-se dos recursos naturais, com ênfase em suas necessidades energéticas, o quadro ambiental do planeta acaba se alterando, em consequência principalmente da utilização de combustíveis fósseis na geração de energia, tendendo ao aquecimento global e outros problemas ambientais derivados.

Nessa conjuntura, Sachs (2011) afirmar que é necessária a substituição das energias fósseis, que são responsáveis por grandes impactos ambientais, pelo leque de energias renováveis, como a solar, a eólica e as bioenergias, pois estas são fontes limpas que não alteram o meio ambiente de forma significativa, quando comparadas aos combustíveis fósseis.

O Brasil, detentor de uma matriz energética hídrica, se viu diante de uma crise energética ocasionada principalmente pela soma de três fatores: a escassez de chuvas, a falta de planejamento e ausência de investimentos na geração e transmissão de energia em 2001. 
Assim, no Brasil, um dos locais que melhor se enquadra para essa produção de energia eólica é o Nordeste, pois o mesmo apresenta características físicas - alta incidência de ventos fortes e constantes - favoráveis a implementação de usinas eólicas. Essa região, atualmente, vem atraindo investimentos estrangeiros subsidiados pelo Banco Nacional de Desenvolvimento Econômico e Social (BNDES), para a implementação de parque eólicos, fábricas e outras infraestruturas referentes a indústria eólica (JUÁREZ et al 2014).

Embora o discurso de sustentabilidade que envolve o processo de geração de eólica de energia seja bem difundido, existem riscos envolvidos desde o seu processo de instalação ao processo de geração. Neste sentido, o licenciamento ambiental e os estudos de viabilidade econômica e ambiental dos empreendimentos chamam atenção para diversos fatores, desde os impactos à avifauna migratória, às respostas sociais e ao arrendamento de terras para instalação das torres eólicas. Essas respostas sociais e ambientais serão avaliadas nesse trabalho através da percepção ambiental.

Para Santos et al. (2007) a palavra percepção vem de "perceber" (percebere do latim), e significa apoderar-se de adquirir conhecimentos por meio dos sentidos, formar ideias, distinguir, notar, ver, ouvir e entender e, cada ser humano tem uma forma individual de perceber o ambiente ao seu redor. A percepção ocorre no momento em que a atividades dos órgãos dos sentidos estão associados com atividades cerebrais (MELAZO, 2005). Ela pode, portanto, ser desenvolvida através da funcionalidade dos sentidos, tornando assim diferente em cada indivíduo, pois, o significado que os estímulos sensoriais despertam é o que distingue a forma como cada indivíduo compreende a realidade em que está imerso (RIBEIRO, 2003).

Castello (2001), sabendo que a vivência humana no ambiente em que está inserido é orientada por sua percepção e pela atribuição de valores, dão sentido ao termo "Percepção Ambiental". Segundo o mesmo autor, percepção ambiental é fundamentada pelo entendimento de que a vivência humana e seu entorno próximo são orientados por essa percepção. Tuan (1980) chega a abordar a questão de indivíduo nativo do ambiente e do indivíduo visitante. Segundo Tuan (1980, p. 67), "O nativo tem uma complexa e derivada percepção do meio por estar inserido nele, baseado em mitos e valores locais" enquanto que o indivíduo visitante levaria em consideração os critérios estéticos, regulados por um juízo de valor inerente ao visitante. 
Com o aumento da urbanização e da intensificação dos problemas ambientais a eles vinculados, ampliam-se as pesquisas relacionadas à preservação e ao planejamento que buscam observar e explicar os padrões comportamentais relacionados ao homem/meio ambiente (KOZEL, 2001).

Assim, o estudo da percepção ambiental se torna fundamental para que possamos compreender melhor as inter-relações entre o homem e o ambiente no qual vive, suas expectativas, satisfações e insatisfações, valores e condutas, como cada indivíduo percebe, reage e responde diferentemente frente às ações sobre 0 meio. O estudo deve buscar não apenas o entendimento do que o indivíduo percebe, mas também promover a sensibilização, a consciência, bem como o desenvolvimento do sistema de compreensão do ambiente ao seu redor (MELAZO, 2005). A percepção ambiental, de modo geral, vem chamando a atenção para um diagnóstico mais profundo através da análise de como a comunidade interpreta 0 ambiente em que vive (BARRETO, 2008).

Portanto, a percepção ambiental também deve estar envolvida nos estudos sobre os riscos e vulnerabilidades. Isso porque, segundo Veyret (2007), o risco pode ser definido como a percepção do perigo, da catástrofe possível. Portanto, o risco não existe sem um indivíduo ou população que o perceba e que possa sofrer os seus danos. Além disso, a autora acrescenta que "o risco e a percepção que se tem dele não podem ser enfocados sem que se considere o contexto histórico que o produziu, as relações sociais e da sociedade com o espaço à sua volta e as formas de ocupação do território" (VEYRET, 2007; p. 26).

Segundo Almeida (2010), o risco é um constructo eminentemente social, ou seja, é uma percepção humana. Risco é a percepção de um indivíduo ou grupo de indivíduos da probabilidade de ocorrência de um evento potencialmente perigoso e causador de danos, cujas consequências são uma função da vulnerabilidade intrínseca desse indivíduo ou grupo (ALMEIDA, 2010).

Segundo Souza e Zanella (2009), as motivações para as pesquisas sobre percepção de riscos são as mais diversas. Por exemplo:

Procura-se compreender como diferentes indivíduos ou grupos sociais percebem os riscos e se comportam diante dele, por que alguns riscos são aceitos e outros são rejeitados, quais são as medidas adotadas pelas pessoas para que possam conviver com 0 perigo e, em primeiro lugar, por que os indivíduos vivem em áreas de risco (SOUZA; ANELLA, 2009; p. 40). 
Portanto, o estudo da percepção ambiental e de riscos se mostra um instrumento de grande valia para a compreensão dos impactos socioambientais da implantação dos parques eólicos na comunidade de Ponta do Mel, entendendo a relação da população com o seu local de moradia e suas formas de entender os problemas às quais estão expostas.

\section{Desenvolvimento}

Identificação e caracterização da área em estudo

O município de Areia Branca, litoral setentrional do estado do Rio Grande do Norte, abrange uma área de $331,156 \mathrm{~km}^{2}$ e uma população de 25.315 hab. correspondendo a 20.317 na zona urbana e 4.998 na zona rural (IBGE, 2010). A área em estudo compreende a comunidade de Ponta do Mel, localizada na zona rural do município e distante aproximadamente $35 \mathrm{~km}$ da zona urbana, correspondendo a 2,6\% da população de Areia Branca (IBGE, 2010).

Ponta do Mel é caracterizada por ser uma área litorânea, predominantemente pesqueira e turística, contando atualmente com a presença de dois Parques Eólicos em operação e uma central geradora solar fotovoltaica que fica localizada entre os parques eólicos (Figura 1).

Figura 1 Mapa de localização da Comunidade de Ponta do Mel, Areia Branca/RN.

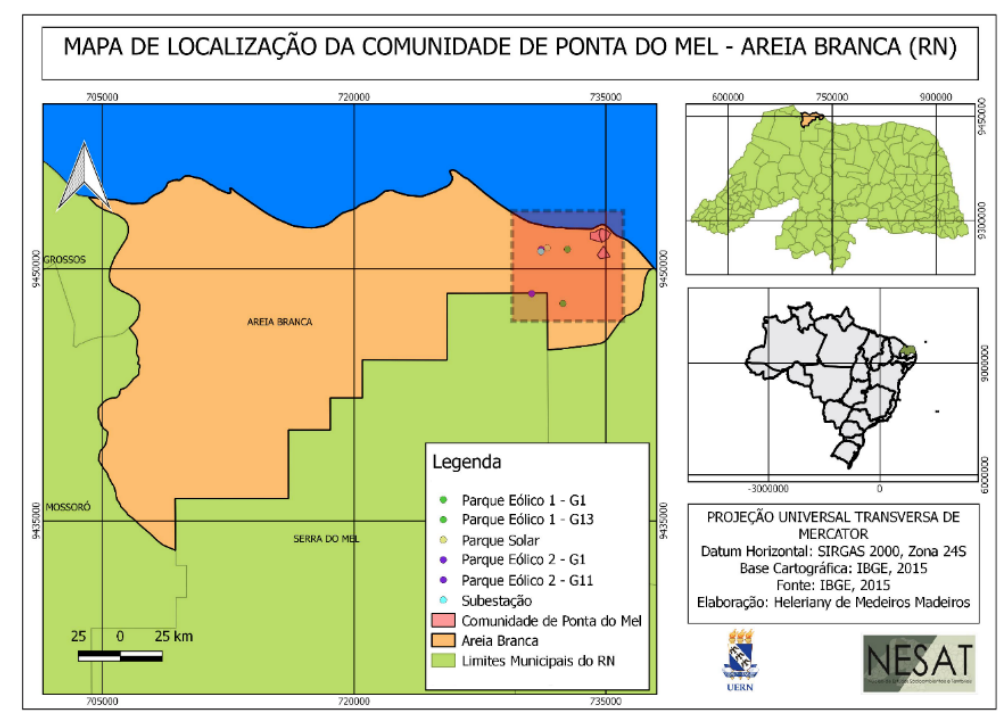

Fonte: Madeiros, 2018.

O município de Areia Branca limita-se ao norte com o Oceano Atlântico, ao sul e leste com os municípios de Serra do Mel e Porto do Mangue, respectivamente, 
e a oeste com os municípios de Grossos e Mossoró (IDEMA, 2008). Na área da economia, Areia Branca possui um Índice de Desenvolvimento Humano Municipal (IDHM) de 0,682 com o PIB per capita (2015) de $\mathrm{R} \$ 24.205,18$. Segundo Vale (2012), a economia em Areia Branca baseia-se na indústria salineira, sendo esta a atividade que mais gera emprego e renda no município. Também merecem constar outras atividades importantes como a pesca e a exploração petrolífera. Nos últimos anos, tem se intensificado outras atividades como a carcinicultura marinha, atividades turísticas e instalação de usinas eólicas (MEDEIROS; CUNHA; ALMEIDA, 2011 ; 2012).

Na educação, segundo o censo escolar (INEP, 2018), o município apresenta um total de 31 escolas, sendo 7 estaduais, 22 municipais e 2 privadas. $O$ censo da educação básica (INEP, 2017), mostra que o número de alunos matriculados em Areia Branca/RN é de 6.041 alunos, sendo 18,9\% matriculados na educação infantil, $60,1 \%$ na educação fundamental, $11,5 \%$ no ensino médio e 9,5\% na educação de jovens e adultos (EJA). Areia Branca apresenta uma taxa de escolarização de 6 a 14 anos de idade de 99,3\% (IBGE,2010), compreendendo a maior parte dessa idade no ensino fundamental, onde estão matriculados o maior número de alunos.

Segundo a Lei $N^{\circ}$ 9.394/96, que estabelece as Diretrizes e Bases da Educação Brasileira (LDB), é dever do Estado, a garantia da educação básica obrigatória e gratuita dos 4 (quatro) aos 17 (dezessete) anos de idade, organizada através da pré-escola, ensino fundamental e médio. Cabendo ao estado, assegurar o ensino fundamental e oferecer, com prioridade, o ensino médio a todos que o demandarem e ao município oferecer a educação infantil em creches e pré-escolas, e, com prioridade, o ensino fundamental. Assim, a rede municipal de ensino em Areia Branca, apresenta um maior número de alunos matriculados, tanto na zona rural como urbana. No município não há escolas estaduais na zona rural, portanto não é oferecido o ensino médio, o que aumenta o número de desistência de concluir o ensino básico, por terem que se deslocarem para a zona urbana de município (Quadro 1).

Quadro 1 Alunos matriculados nas redes públicas e privado do munícipio de Areia Branca/RN

\begin{tabular}{|c|c|c|c|c|c|c|}
\hline \multicolumn{7}{|c|}{ Alunos matriculados na rede pública e privado de Areia Branca } \\
\hline \multirow{3}{*}{$\begin{array}{c}\text { Total de } \\
\text { matriculados }\end{array}$} & \multicolumn{3}{|c|}{ Zona Urbana } & \multicolumn{3}{|c|}{ Zona Rural } \\
\hline & Rede & Rede & Rede & Rede & Rede & Rede \\
\hline & Municipal & Estadual & Privado & Municipal & Estadual & Privado \\
\hline
\end{tabular}




\begin{tabular}{|c|c|c|c|c|c|c|c|}
\hline Creche & 466 & 241 & 0 & 100 & 125 & 0 & 0 \\
\hline Pré Escola & 673 & 312 & 0 & 169 & 192 & 0 & 0 \\
\hline Ensino & & & & & & & \\
\hline Fundamental & 3.630 & 1.473 & 748 & 743 & 666 & 0 & 0 \\
\hline Ensino Médio & 696 & 0 & 581 & 115 & 0 & 0 & 0 \\
\hline EJA & 576 & 121 & 440 & 0 & 15 & 0 & 0 \\
\hline
\end{tabular}

Fonte: Adaptada pela autora, INEP, 2017.

Em relação as características físicas do município, Areia Branca apresenta variações climáticas que vão do árido ao semiárido, com período chuvoso compreendido entre os meses de fevereiro e maio, onde as precipitações anuais têm média de $691,8 \mathrm{~mm}$. A temperatura média anual é de $27,3^{\circ} \mathrm{C}$ e a umidade relativa anual média é de aproximadamente 69\% (IDEMA, 2008). Essas variações climáticas podem ser explicadas pela movimentação da Zona de Convergência Intertropical (ZCIT), onde os períodos de seca estão relacionados com o afastamento da costa, provocando ausência de chuvas e domínio de ventos fortes, enquanto que os períodos chuvosos são ligados ao seu deslocamento para o sul relacionando-se com ventos mais brandos.

Quanto ao relevo do município, este apresenta cota de menos de $100 \mathrm{~m}$ de altitude, sendo caracterizado por planície costeira formada por praias que têm como limites, de um lado, o mar, e, de outro, os tabuleiros costeiros, estendendo-se por todo o litoral. Esses terrenos planos são alterados em suas formas pela presença de dunas, que chegam até 80 metros de altura (IDEMA, 2008). Já a planície fluvial é formada pelo Rio Apodi, e corta no sentido Norte-Nordeste/Sul-Sudoeste toda a área, sua desembocadura, em forma de delta, possui uma ampla região de várzea, permitindo constantes e proeminentes penetrações marinhas.

A vegetação no município é do tipo litorânea e caatinga. A vegetação litorânea é localizada na parte norte e norte-nordeste do município, a qual sofre influência direta das marés (água do mar, salinidade, temperatura e etc.) sendo representado pelo manguezal, sistema ecológico costeiro tropical, dominado por espécies vegetais - mangues e animais típicos aos quais se associam outras plantas e animais, adaptadas a um solo periodicamente inundado pelas marés, com grande variação de salinidade e restinga, do ponto de vista geomorfológico, é considerada um depósito arenoso de origem marítima, apontada pelo Código Florestal como vegetação de preservação permanente. (IDEMA, 2008). 
Outro tipo de vegetação encontrada na região é a da caatinga hipoxerófila, uma vegetação de caráter mais seco, com abundância de cactáceas e plantas de porte mais baixo e espalhadas, podendo destacar as espécies: jurema-preta (Mimosa acutistipulate (Mart.) Benth), mufumbo (Combretum leprosum Mart.), faveleira (Cnidoscolus quercifolius Pohl.), marmeleiro (Croton sonderianus Mull. Arq), xique-xique (Pilosocereus gounellei subsp. Zehntneri (Britton \& Rose) Zappi) e facheiro (Pilosocereus pachycladus subsp. Pernambucoensis (F. Ritter) Zappi).

$\mathrm{Na}$ área de estudo, o tipo de solo predominante é o latossolo vermelho amarelo eutrófico (IDEMA, 2008), caracterizado por uma fertilidade de média à alta, textura média e fortemente drenado. Apresenta-se em relevos planos pouco cultivados, porém podendo ser intensamente aproveitados para agricultura no "inverno" devido ao problema de falta d'água, que é um fator limitante, em razão do longo período de estiagem e da grande evaporação. Apesar de serem pouco cultivados, podem ser observadas culturas de feijão, milho e mandioca, isso porque a aptidão agrícola é restrita para lavouras e aptas para culturas de ciclo longo como algodão arbóreo, sisal, caju e coco. A área baixa é indicada para preservação da flora e fauna ou para recreação.

Em relação aos recursos hídricos da região, o município encontra-se com $62 \%$ do seu território inserido na Bacia Hidrográfica Apodi - Mossoró, e 38\% na Faixa Litorânea Norte de Escoamento Difuso, sendo banhado à Noroeste, pela subbacia do rio Morro Branco e a Norte pelo Oceano Atlântico. Também ao Norte existe o açude Salgada, o principal do município, não possuindo açudes com capacidade de acumulação igual ou superior a 100.000m3 sendo um padrão de drenagem dendrítico (CPRM, 2005).

Durante a pesquisa, o Estado do Rio Grande do Norte, através do Decreto Estadual No 27.695/2018, criou uma Área de Proteção Ambiental (APA) Dunas do Rosado, compreendendo os Munícios de Porto do Mangue e Areia Branca. Sendo essa a primeira unidade de conservação do município de Areia Branca/RN. A APA Dunas do Rosado possui 16.593,7 (dezesseis mil, quinhentos e noventa e três hectares e sete ares) de extensão e foi criada com o objetivo de proteger a diversidade biológica, disciplinas o processo de ocupação e assegurar a sustentabilidade do uso dos recursos naturais, onde abriga biomas da caatinga, campos dunares, tabuleiros costeiros e estuários. O processo de criação da APA levou 12 anos para ser concluído, durante esse longo período, seis empreendimentos eólicos foram instalados em Areia Branca, entre os anos de 2013 
à 2015, ocasionando conflitos nas comunidades pesqueiras do município, o que poderia ter sido evitado caso a APA tivesse sido criada antes desse período (Figura 2).

Figura 2 Mapa da Área de Proteção Ambiental Dunas do Rosado - RN

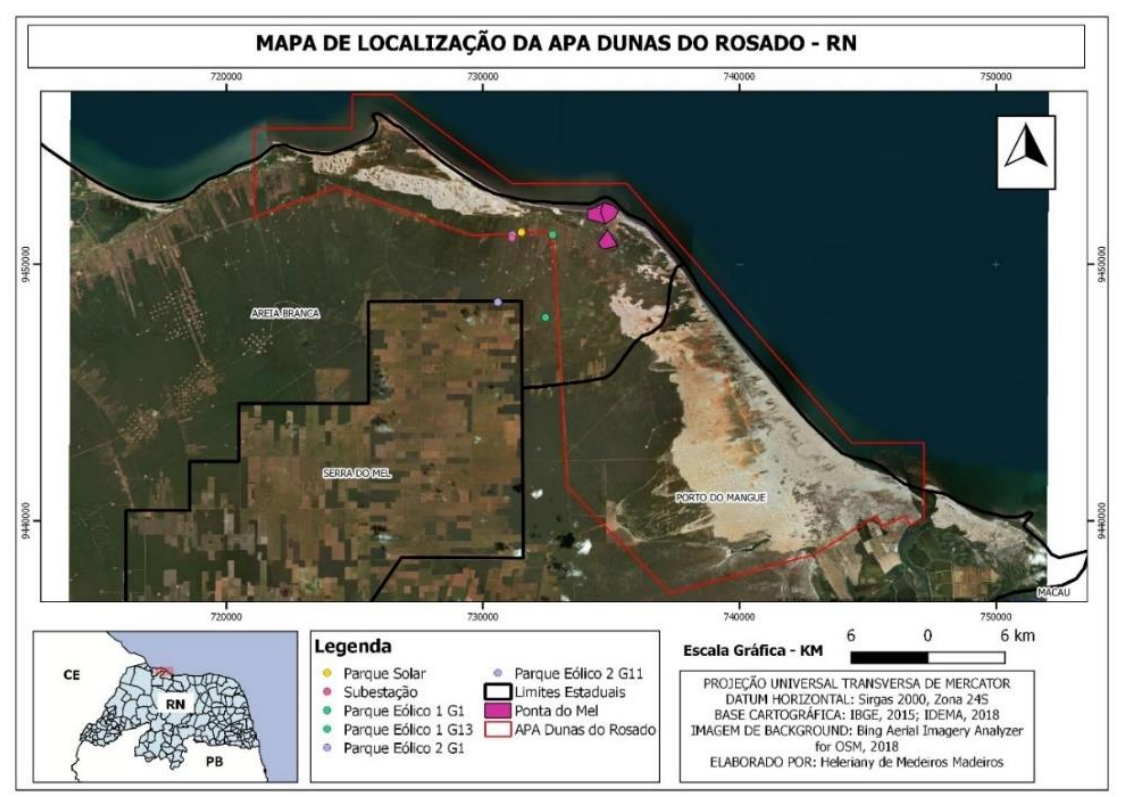

Fonte: Madeiros, 2018.

\section{Procedimentos metodológicos}

Para a realização deste estudo, buscou-se realizar uma pesquisa bibliográfica no que se refere especificamente à geração de energia eólica e a percepção ambiental, foram utilizados artigos científicos indexados em bases de dados nacionais e internacionais, a saber: Scielo (www.scielo.br), Scopus (www.scopus.com) e Web of Science (www.webofknowledge.com). Dissertações, teses, websites especializados.

Foram aplicados um questionário com 10 (dez) questões na comunidade (quadro 2), buscando-se organizar, fundamentar, comparar e analisar as percepções sobre os impactos socioambientais dos Parques Eólicos na área litorânea. A pesquisa foi realizada em 70 domicílios da comunidade de Ponta do Mel, que de acordo com o censo do IBGE, realizado em 2010, apresenta 477 domicílios particulares permanentemente ocupados, divididos em três setores censitários, sendo um desses setores um assentamento agrícola, do Instituto Nacional de Colonização e Reforma Agrária (INCRA).

Para que a aplicação dos questionários tivesse precisão, utilizamos os três setores censitários 240110705000018, 24011070500017 e o 24011070500023, delimitados pelo IBGE, para a comunidade de Ponta do Mel, abrangendo uma 
população de 477 domicílios, sendo respectivamente 191 domicílios do primeiro setor, 190 do segundo e 96 do terceiro. Após aplicação das variáveis na fórmula estatística descrita por Triola (1999), os questionários foram aplicados nesses três setores censitários, considerando os domicílios particulares permanentes, sendo a proporção de 25 na área que a população denomina de Ponta do Mel, primeiro setor censitário mais próximo da praia; 25 na área do Novo Mel, parte mais elevada da comunidade que corresponde ao segundo setor e 20 na área do assentamento agrícola, denominado Serra, que correspondem ao terceiro setor.

Quadro 2 Questionário de percepção ambiental aplicado na comunidade de Ponta do $\mathrm{Mel} / \mathrm{RN}$.

1. A comunidade foi informada sobre os benefícios e possíveis danos causados pela atividade eólica na comunidade?

2. A comunidade recebe algum apoio (governo, ONGs, Ministério Público) para lidar com problemas relacionados a energia eólica?

( ) Sim ( ) Não Se sim, de quem?

3. A comunidade possui organização para lidar com problemas relacionados a atividade eólica ou outra(s)?

4. A comunidade recebeu compensações econômicas, educacionais e de saúde pela instalação do parque eólico na comunidade?

5. Alguém na sua família foi empregada no parque eólico? Se sim, em que fase?

( ) Instalação da atividade ( ) Operacionalização da atividade

6. Famílias que residem próximas ao parque eólico recebem algum tipo de benefício financeiro?

7. Sua circulação é permitida por dentro do parque eólico?

8. Você percebe a geração de algum problema ambiental causado pelo parque eólico na comunidade?

Se sim, qual(is):

9. Existem ou ocorreram conflitos em relação a posse das terras utilizadas para instalação da atividade na comunidade?

Se sim, qual(is)?

10. Atualmente conhecendo as informações sobre a atividade dos parques eólicos você apoiaria a instalação da atividade na localidade?

Fonte: Autora, 2019.

Os domicílios foram selecionados de forma aleatória, e os questionários foram aplicados aos chefes de família de ambos os sexos, sendo como critério a condição 
de ser o principal ou único mantenedor do domicílio. As entrevistas aconteceram em dois dias entre os meses de fevereiro e março de 2018.

Através da percepção socioambiental da comunidade sobre os impactos do parque eólico, pretendeu-se investigar a satisfação dos entrevistados quanto os benefícios da instalação dos parques eólicos na comunidade, sobre o modo de organização social perante a algum problema relacionados aos empreendimentos eólicos, a relação entre a comunidade e o empreendimento, e o apoio a novos empreendimentos eólicos na comunidade. $O$ estudo classifica-se como primário, em relação à obtenção dos dados; quali-quantitativo, quanto à sua abordagem; e descritivo quando à sua natureza.

Portanto, a análise de dados consistirá da utilização de métodos qualiquantitativos, que segundo Richardson (2008) considera que, a partir da contextualização histórica e da construção social dos fenômenos existentes, a pesquisa do tipo qualitativa possibilita a investigação e a análise crítica dos fenômenos sociais e ambientais.

\section{Resultados e discussão}

A percepção sobre os impactos socioambientais foi coletada através da aplicação do questionário. Pelo questionário foi possível apreciar mudanças ocorridas na comunidade por meio das percepções sobre os principais eventos relacionados à implantação e ao funcionamento dos parques eólicos da comunidade de Ponta do Mel, bem como realizar a análise histórica das informações contidas nos discursos.

Quando questionados se foram informados quanto aos benefícios e danos que a instalação dos parques eólicos causaria na comunidade, 27,14\% disseram que não foram informados, 17,14\% não souberam informar e 55,71\% disseram foram informados através de palestras nas escolas e associações, porém desses, $30,76 \%$ disseram que foram passados apenas os benefícios, citando a geração de empregos temporários. Loureiro, Gorayeb e Brannstrom (2017), demostram como os líderes disseminam a ideia favorável aos impactos econômicos positivos, no que tange a geração de emprego, portanto, por não ter uma mão de obra qualificada, a população local é pouco afetada economicamente.

Isso reflete diretamente na relação da comunidade com o empreendimento, pois segundo $90 \%$ dos entrevistados, a comunidade não recebe nenhum apoio das instituições públicas ou ONGs para lidar com problemas gerados pelos parques 
eólicos. Quando questionados a respeito da organização que a comunidade tem para lidar com problemas relacionados aos parques eólicos, $72,42 \%$ responderam que não existe nenhum tipo de organização e 17,14\% não souberam informar. Um dos conflitos relatados pela comunidade, foram que algumas empresas eólicas, deixaram de pagar alugueis das casas, gerando um transtorno para quem dependia dessa renda. Apenas $11,42 \%$ responderam que existe organização, mais não citaram quais.

Costa (2015) retrata que em João Câmara/RN, uma das formas encontradas para gerar renda pelos moradores, foi a locação de casas para os colaboradores dos parques eólicos na região. Muitas vezes as famílias iam morar junto com outros parentes e alugavam suas casas, aumentando assim no município a crescente especulação imobiliária. Essa especulação também foi observada na pesquisa de Hofstaetter (2016), onde um entrevistado cita que casas que antes eram alugadas por $R \$ 50,00$, depois que as empresas de eólicas chegaram ao município passaram a serem alugadas por $R \$ 500,00$, também foi visto que como em Ponta do Mel, no município de João Câmara, empresas foram embora e deixaram dividas de alugueis.

Moreira, Bizarria, Marquesan e Barbosa (2017) explica que há dois aspectos intrigantes sobre a construção dos parques no interior do Ceará: um deles diz respeito à falta de discussão com a comunidade; o outro, à dificuldade de manter um diálogo com as empresas sobre o processo de implantação e os impactos nas comunidades mais diretamente afetadas, sendo esses aspectos também observados na comunidade de Ponta do Mel, onde moradores foram prejudicados pela falta de pagamento e não tinham a quem recorrer.

Outro aspecto observado durante a instalação do parque, foram que $70 \%$ dos entrevistados disseram que não ocorreram compensações econômicas, educacionais e de saúde com a instalação do parque na comunidade e 12,85\% não souberam responder quando questionados. Apenas 17,14\%, reconheceram alguma compensação citando aspectos pontuais como a entrega de kits escolares, um consultório móvel para atendimento odontológico e a doação de computadores.

Nascimento (2014) mostra que a política de financiamento e liberação de crédito do Banco Nacional de Desenvolvimento Econômico e Social - BNDS para instalação e operação de parques élicos, estabelece que até $1 \%$ do valor deve ser destinado a implantação de projetos que promova a preservação, conservação e recuperação das condições essenciais para a humanidade. Através dessa exigência, a empresa implantou junto com a secretaria de Ação Social de Areia Branca/RN, 
uma biblioteca comunitária e um espaço digital (Figura 3), ambos ligados ao programa de interação familiar denominado de Centro de Convivência da Família CECOF. Onde segundo coordenadora do local visitado, são atendidas 90 crianças (através de oficinas de capoeira, música, dança, teatro, esportes, informática e atividades diversas na biblioteca) e 35 idosos (atendimento psicológico, palestras, ginastica e artesanato), com o objetivo de promover a interação de crianças e adolescentes com suas famílias e com o ambiente escolar. Porém, a empresa fez apenas a doação dos livros e computadores e o município é responsável pela gestão, onde a equipe que coordena o programa comporta por 3 pedagogas e colaboradores, alega dificuldades na manutenção e desenvolvimento das oficinas por não possuírem recursos que garantam meios de manter o público assíduo (NASCIMENTO, 2014).

Portanto, poucos entrevistados conhecem esse projeto implantado pelos parques eólicos na comunidade e as empresas continuam, através de projetos pontuais, cumprindo exigências dos bancos financiadores e condicionantes da licença ambiental sem nenhum acompanhamento por partes dos órgãos fiscalizadores.

Figura 3 Espaço digital e biblioteca implantadas pelos Parques Eólicos na comunidade de Ponta do Mel, Areia Branca/RN.
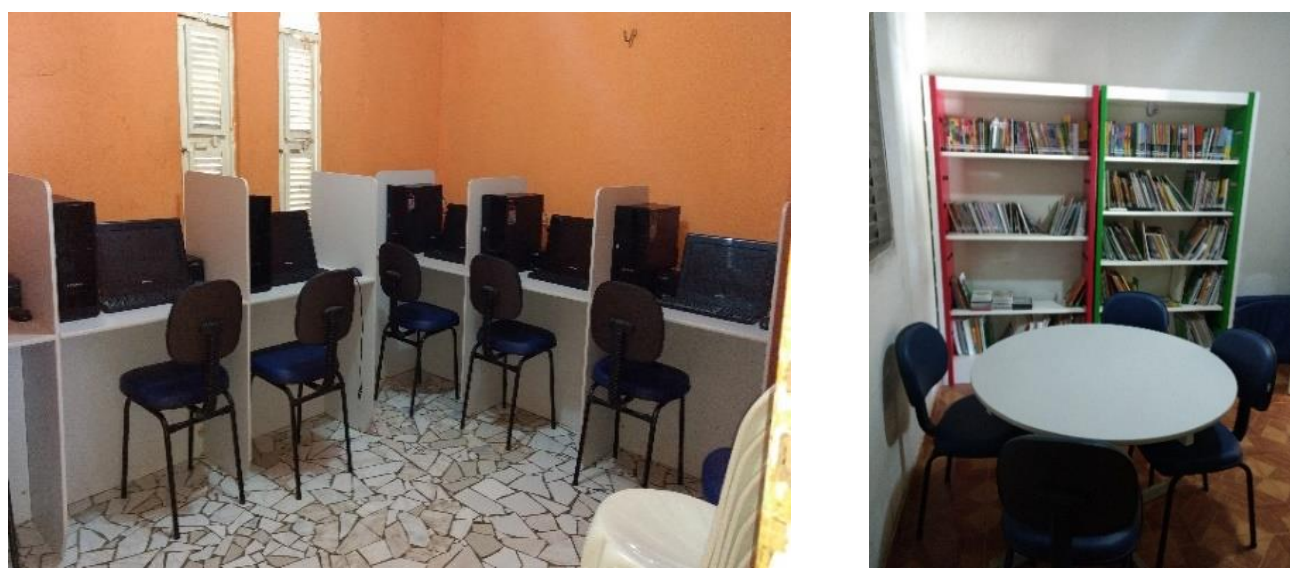

Fonte: Autora, 2018.

Dentre os entrevistados, quando perguntados sobre se algum membro da família foi empregado nas obras dos parques eólicos, $57,14 \%$ disseram que não houveram empregos gerados para os membros e $42,85 \%$ confirmaram que houveram membros empregados, desses $83,33 \%$ disseram que a fase da obra que mais empregou foi na instalação dos parques, devido as obras de construção civil e 
desmatamento, e apenas 13,33\% responderam que ficaram na fase de operação, esse número correspondendo a quatro entrevistados.

Hofstaetter (2016), relata que em João Câmara/RN, os empregos gerados foram apenas na instalação dos parques, sendo esses sazonais (de 6 a 18 meses) e caracterizados por baixa remuneração, principalmente pela desqualificação da mão de obra local, onde ficam restritos a postos de Auxiliar de Serviços Gerais - A, pedreiros e vigias.

Quanto aos benefícios financeiros, foi perguntando aos entrevistados, se famílias que moram próximo aos parques eólicos recebem algum tipo de benefícios, $72,85 \%$ responderam que não recebem, apenas os donos de terras, através de arrendamento de terras e 24,28\% dizem não conhecer tal assunto. Apenas 2,85\% disseram que a comunidade próximos aos parques, recebem benefícios pela instalação dos parques.

Essa é uma da questão mais polêmica e que geram maior conflito nas comunidades, pois, após identificar a área de interesse para implantação dos projetos eólicos, procura-se o proprietário para apresentação do projeto e as condições do arrendamento. Com os termos de arredamento aceitos pelo proprietário, ele assina o contrato de arrendamento e averbação do mesmo na matricula do imóvel. Quando a propriedade não tem regularidade fundiária (matrícula no cartório) é realizada avaliação jurídica do caso, dando início ao processo de usucapião. Staut (2011) relata na sua pesquisa que o empreendedor negociou a terra para arrendamento com uma advogada da cidade, porém, as terras pertenciam a uma associação de moradores e não a advogada, gerando um conflito na região.

Dentro desses conflitos em relação a arrendamento de terras, foi questionado se a circulação da comunidade era permitida por dentro da área do parque, apenas $11,42 \%$ dos entrevistados disseram ter acesso livre, os outros $88,57 \%$ disseram não ter acesso, apenas com autorização e agendamento prévio ou não saber informar. Freitas (2018) constatou que na comunidade pesquisada, não existe cercas ou placas de proibição, mais a vigilância é frequente e intimida as pessoas que transitam na área. Pinto, Nascimento, Bringel e Meireles (2014) cita dentro dos impactos ambientais gerados pela instalação dos parques eólicos, a privatização das áreas utilizadas pela comunidade e a proibição do acesso à praia, como os dos principais conflitos gerados na comunidade.

Quanto aos conflitos da comunidade de Ponta do Mel, em relação a posse de terras, $67,14 \%$ disseram não haverem conflitos, pois a propriedade já era privada, 
$14,28 \%$ não souberam responder e apenas $17,14 \%$ identificaram conflitos como a desapropriação de casas.

Desse modo, quando questionados a respeito da geração de algum problema ambiental gerados pela instalação dos parques na comunidade de Ponta do Mel, $48,57 \%$ disseram que não perceberam problemas e $2,85 \%$ não souberam opinar. Portanto, 48,57\% perceberam impactos ocasionados pela instalação do parque, dentre eles os mais citados foram: desmatamento e afugentamento/mortalidade da fauna, identificando a perda da biodiversidade na região. Loureiro, Gorayeb e Brannstrom (2015) relata que o desmatamento promove a supressão dos ambientes com fauna e flora específicos de dunas e tabuleiro interrompendo assim os fluxos de matéria e energia com a construção de vias de acesso ao aerogeradores, provocando a destruição de habitats naturais.

Após o levantamento de todas as informações a respeito da implantação de parques eólicos na comunidade de Ponta do Mel, foi questionado a comunidade se apoiaria a instalação de novos parques no local e $85,71 \%$ se disseram favorável a instalação, onde alguns citaram a geração de emprego e renda. Apesar de 42,85\% dos entrevistados ter dito anteriormente, que algum membro da família foi empregado nos parques, a comunidade caracteriza-se por autônomos como já mostrado, o que aprova esses empregos temporários que o parque ofereceu.

Os $12,85 \%$ que não aceitam a instalação de novos parques, relatam não aceitar devido aos prejuízos com o meio ambiente, que apesar de gerar empregos não contribuiu com a comunidade e causou prejuízos a alguns comerciantes (como o não pagamento de alugueis de casas e alimentação). Freitas (2018) relatou que a maioria da comunidade não apoia a implantação de novos parques na localidade, ou seja, apesar de serem comunidades vizinhas, os parques da comunidade de São Cristovão, estão muito próximos a comunidade, já na comunidade de Ponta do Mel, onde a autora desenvolveu a pesquisa, os parques encontram-se distantes, impactando menos no dia-a-dia da comunidade.

\section{Considerações Finais}

Por meio das percepções socioambientais da comunidade em relação as atividades dos parques eólicos, foi possível verificar que o diálogo entre 0 empreendedor e a comunidade é apenas a respeito dos benefícios que os parques trariam ao meio de vida da comunidade e que caso o empreendimento causassem mais danos do que benefícios a população, os mesmos não teriam a quem recorrer, 
pois não contam com apoio de nenhuma entidade e nem mantem nenhuma organização para lidar com problemas oriundos dos parques ou de qualquer outro empreendimento que venha a se instalar nas proximidades.

Os impactos observados com a instalação dos parques eólicos na comunidade, foram bem pontuais, como: a falta de pagamento de aluguel de imóveis e alimentação. A população também identificou, de forma bem pontual, algumas compensações como a entrega de kits escolares, um consultório móvel para atendimento odontológico e a doação de computadores.

Portanto, em geral a população achou favorável para comunidade os empregos temporários gerados e apoia a instalação de novos parques eólicos na comunidade, até porque não houveram conflitos significativos entre a comunidade e os parques, por esses estarem mais distantes de Ponta do Mel/RN, identificando como principal impacto para a região a questão do desmatamento, que é um dos principais impactos observados por vários autores que trabalham com essa temática.

\section{REFERÊNCIAS}

ALMEIDA, L. Q. Vulnerabilidades Socioambientais de Rios Urbanos: Bacia

Hidrográfica do Rio Maranguapinho, Região Metropolitana de Fortaleza, Ceará. Tese de Doutorado. Programa de Pós-Graduação em Geografia. Rio Claro/SP, 2010.

BARRETO, K. F. B. Impactos da intervenção do projeto "Doces Matas" em comunidades de Mata Atlântica: perspectiva de um estudo de percepção ambiental. Sergipe, 2008, f. 132. Dissertação (Mestrado em Desenvolvimento e Meio Ambiente) Programa de Pós-Graduação em Desenvolvimento e Meio Ambiente PRODEMA, Universidade Federal de Sergipe, Sergipe, 2008.

CASTELLO, L. Percepção do ambiente educando educadores. Percepção ambiental: a interdisciplinariedade no estudo da paisagem, OLM - Ciência e Tecnologia, Rio Claro, V.1, n 2, p. 153-165, nov, 2001.

COSTA, R. F. Ventos que transformam? Um estudo sobre o impacto econômico e social da instalação dos parques eólicos no Rio Grande do Norte/Brasil. 2015. 212 f. Dissertação (Mestrado em Estudos Urbanos e Regionais) - Universidade Federal do Rio Grande do Norte, Natal, 2015.

CNMAD, Comissão Mundial sobre Meio Ambiente e Desenvolvimento. Nosso Futuro Comum. 2. Ed. Rio de Janeiro: Editora da Fundação Getúlio Vargas - FGV, 1991. CPRM, Companhia de Recursos Minerais. Projeto cadastro de fontes de abastecimento por águas subterrâneas. Diagnóstico do município de Areia Branca, estado do Rio Grande do Norte. Recife, PE: CPRM/PRODEEM, 2005. Disponível em:

http://rigeo.cprm.gov.br/xmlui/bitstream/handle/doc/16239/rel_areia_branca.pdf?sequence=1 . Acesso em: 8 fev. 2018.

FREITAS, Stênio Felix. Índice de Vulnerabilidade Socioambiental para Atividades dos Parques Eólicos, Percepção e Impactos Ambientais na Comunidade de São Cristovão, Areia Branca - RN. Dissertação de Mestrado Programa de Pós-Graduação em Ciências Naturais. UERN. Mossoró/RN, 2018.

HOFSTAETTER, M. Energia eólica: entre ventos, impactos e vulnerabilidades socioambientais no Rio Grande do Norte. 2016. 176 f. Dissertação (Mestrado em Estudos Urbanos e Regionais) - Universidade Federal do Rio Grande do Norte, Natal, 2016. 
IBGE. Instituto Brasileiro de Geografia e Estatística, 2010. Disponível em:

https://cidades.ibge.gov.br/brasil/rn/areia-branca/panorama. Acesso em: 10 de maio de 2017.

IDEMA, Instituto de Desenvolvimento Sustentável e Meio Ambiente do Rio Grande do Norte. Perfil do seu município: Areia Branca. Natal, RN, 2008. Disponível em:

http://adcon.rn.gov.br/ACERVO/idema/DOC/DOC000000000016658.PDF. Acesso em: 14 fev. 2018.

INEP, Instituto Nacional de Estudos e Pesquisas Educacionais Anísio Teixeira, 2017. Disponível em: http://portal.inep.gov.br/web/guest/sinopses-estatisticas-da-educacao-basica . Acesso em: 05 de janeiro de 2019.

INEP, Instituto Nacional de Estudos e Pesquisas Educacionais Anísio Teixeira, 2018. Disponível em: http://portal.inep.gov.br/artigo/-

/asset_publisher/B4AQV9zFY7Bv/content/definido-o-cronograma-do-censo-escolar2018/21206. Acesso em: 05 de janeiro de 2019.

JUÁREZ, A. A.; ARAÚJO, A. M.; ROHATGI, J. S.; OLIVEIRA FILHO, O. D. Q. Development of the wind power in Brazil: Political, social and technical issues. In: Renewable and Sustainable Energy Reviews, v. 39, p. 828-834, jul-nov, 2014.

KOZEL, S. T. Das imagens às linguagens do geográfico: Curitiba, a " Capital ecológica". Tese de doutorado. Departamento de Geografia. USP.SP, 2001. LOUREIRO, C. V.; GORAYEB, A.; BRANNSTROM, C. Análise comparativa de políticas de implantação e resultados sociais da energia eólica no Ceará (Brasil) e no Texas (EUA). Revista RAEGA - O Espaço Geográfico em Análise. Curitiba, v.40, p. 231 -247, Ago/2017. LOUREIRO, C. V.; GORAYEB, A.; BRANNSTROM, C. Implantação de energia eólica e estimativa das perdas ambientais em um setor do litoral oeste do Ceará, Brasil.

Geosaberes: revista de estudos geoeducacionais, Fortaleza, v. 6, n. 1, p. 24 - 38, jul. 2015. Disponível em: http://www.geosaberes.ufc.br/geosaberes/article/view/361. Acesso em: 06 fev. 2018.

NASCIMENTO, B. T. C. O Papel do Bibliotecário em Áreas de Influência Indireta dos Parques Eólicos no Rio Grande do Norte: Implantação da Biblioteca Comunitária Mar e Terra. Natal: UFRN, 2014.

MEDEIROS, W. D. A.; CUNHA, L.; ALMEIDA, A. C. Dinâmica territorial e impactos ambientais no município de Areia Branca-RN (nordeste do Brasil): uma análise preliminar. Revista Geográfica de América Central. Número Especial EGAL, Costa Rica, pp. 1-14, 2011.

MEDEIROS, W. D. A.; CUNHA, L.; ALMEIDA, A. C. Riscos Ambientais e percepção no litoral: estudo comparativo Brasil-Portugal. Revista Geonorte, Edição Especial, v.1, n.4, p985-997, 2012.

MELAZO, G.C. A percepção ambiental e educação ambiental: uma reflexão sobre as relações interpessoais e ambientais no espaço urbano. Olhares \& Trilhas. Uberlândia, Ano VI, n. 6, p. 45-51, 2005.

MOREIRA, R.N; BIZZARRIA, F.P.A; MARQUESAN, F.F.S; BARBOSA, F.L.S.

Sustentabilidade e energia eólica: percepções comunitárias no interior do Ceára - Brasil.

COLÓQUIO - Revista do Desenvolvimento Regional - Faccat - Taquara/RS - v. 14, n. 1, jan./jun. 2017.

PINTO, M.F.; NASCIMENTO, J.L.J.; BRINGEL, P.C.F.; Meireles, A.J.A. (2014). Quando os conflitos socioambientais caracterizam um território? Gaia Scientia (ISSN: 1981 -1268), Ed. Espe. Populações tradicionais: 272 - 288. João Pessoa, PB, Brasil. Disponível on-line em http://periodicos.ufpb.br/ojs2/index.php/gaia/index

RIBEIRO, L. M. O papel das representações sociais na educação ambiental.

Dissertação de Mestrado, pela Pontifícia Universidade Católica. Departamento de

Educação. Programa de Pós-Graduação em Educação. Rio de Janeiro, 2003.

RICHARDSON, Roberto Jarry. Pesquisa social: métodos e técnicas. $3^{\underline{a}}$ ed. São Paulo:

Atlas, 2008.

SACHS Ignacy. Energias Renováveis no Brasil: desafios e oportunidades. Santos, SP: Editora Brasileira de Arte e Cultura, 2011. 
SANTOS, M. M. de et al. Percepção ambiental da população do entorno do Parque Estadual Xixová-Japuí (PEXJ). In: MEDEIROS, R. \& IRVING, M.A. (orgs.). Áreas Protegidas e Inclusão Social: Tendências e perspectivas, V (3), 2007.

SOUZA, L. B.; ZANELLA, M. E. Percepção de Riscos Ambientais: Teoria e Aplicações. Fortaleza: Edições UFC, 2009.

STAUT, Fabiano. O Processo de Implantação de Parques Eólicos no Nordeste Brasileiro. Dissertação de Mestrado. Programa de Pós-Graduação em Engenharia Ambiental Urbana. Salvador, 2011.

TAGLIANI, C. R. A. A mineração na porção média da Planície Costeira do Rio Grande do Sul: estratégia para a gestão sob um enfoque de Gerenciamento Costeiro Integrado. Tese de Doutorado. Programa de Pós-Graduação em Geociências. UFRGS. Rio Grande do Sul - RS. 252 p. 2002.

TRIOLA, Mário F. Introdução à estatística. 7.ed. Rio de Janeiro-RJ: LTC. 1999.

TUAN, Yi-Fu. Topofilia: um estudo da percepção, atitudes e valores do meio ambiente. São Paulo: Difel, 1980.

VALE, M. N. Um estudo acerca da utilização do tempo disponível dos idosos em Areia Branca/RN. Turismo: Estudos e Práticas - UERN, Mossoró/RN, vol. 1, n. 2, jul./dez. 2012. VEYRET, Y. Os riscos: o homem como agressor e vítima do meio ambiente. São Paulo: Contexto, 2007.

\section{NOTAS DE AUTOR}

\section{CONTRIBUIÇÃO DE AUTORIA.}

Fabiana Silva Medeiros Ferreira - Concepção. Coleta de dados, Análise de dados, Elaboração do manuscrito, revisão e aprovação da versão final do trabalho

Ramiro Gustavo Valera Camacho - Coleta de dados Participação ativa da discussão dos resultados; Revisão e aprovação da versão final do trabalho.

Rodrigo Guimarães de Carvalho - Participação ativa da discussão dos resultados; Revisão e aprovação da versão final do trabalho.

\section{FINANCIAMENTO}

Não se aplica.

\section{CONSENTIMENTO DE USO DE IMAGEM}

Não se aplica.

\section{APROVAÇÃO DE COMITÊ DE ÉTICA EM PESQUISA}

Teve aprovação do comitê de ética, parecer 2.511.046 de 24 de fevereiro de 2018.

\section{CONFLITO DE INTERESSES}

Não se aplica.

\section{LICENÇA DE USO}

Este artigo está licenciado sob a Licença Creative Commons CC-BY. Com essa licença você pode compartilhar, adaptar, criar para qualquer fim, desde que atribua a autoria da obra.

\section{HISTÓRICO}

Recebido em: 17-01-2019

Aprovado em: 30-07-2019 